\title{
As instituições e a via da dependência histórica
}

Diana Carolina Valencia Tello ${ }^{1}$

\section{Resumo}

O fortalecimento do Estado deve começar por cada uma das entidades públicas que o compõem, mediante a compreensão das diferentes instituições formais e informais existentes em cada uma delas, assim como também dos mecanismos de cumprimento existentes das regras estabelecidas. Só compreendendo cada instituição dentro do respectivo contexto cultural, é possível direcionar acertadamente o desenvolvimento e a eficácia das atuações estatais. Assim, o presente trabalho analisará o papel das instituições no progresso ou no estancamento das sociedades, enfatizando a importância de reconhecer as limitações históricas existentes em cada sociedade e em cada instituição com a finalidade de melhorar a efetividade das políticas públicas e das ações estatais. Para isso, no primeiro capítulo, será analisado o conceito de instituição, no segundo, uma curta retomada da Revolução Americana, da Revolução Francesa e do Caso Latino Americano, com a finalidade de mostrar como as mudanças nas leis formais não são suficientes para criar instituições que promovam o bem-estar da sociedade e, no terceiro capítulo, uma tentativa de estabelecer parâmetros básicos e gerais que as instituições públicas deveriam cumprir para conseguir maior efetividade dentro da sociedade em que se desenvolve. Em nosso conceito, é importante começar a trabalhar na construção de diferentes mecanismos de reeducação da sociedade, especialmente no interior das entidades públicas, para as quais é muito importante que as universidades e centros educativos ajudem na construção de programas e espaços em curto, médio e longo prazos, e ajudem na monitoração e avaliação de instituições específicas.

Palavras-chave: Instituições. Efetividade de políticas públicas. Reeducação das entidades públicas. Dependência histórica.

1 Mestranda em direito pela Universidade Federal do Paraná, bolsista Capes. Graduada em direito pela Universidad Colégio Mayor de Nuestra Señora del Rosário (Bogotá, Colômbia), 2002. 


\section{Introdução}

$\mathrm{Na}$ atualidade não existe dúvida sobre a necessidade e a importância do Estado para o desenvolvimento social e econômico da sociedade, o que lhe tem outorgado competência para intervir em um sem número de atividades em meio de interesses discordantes. Essa intervenção sempre vai implicar em negação de algum interesse individual ou grupal, já que nas sociedades atuais o consenso total é completamente irreal, uma utopia.

Nessa conjuntura, hoje mais que em nenhuma outra época, é prioritário ajudar na construção de Estados mais justos, que promovam o bem-estar e a prosperidade geral de todos os cidadãos, já que a captura do Estado por parte de interesses privados coloca em grave risco a governabilidade e a democracia necessárias para a estabilidade dos governos.

Em nosso conceito, o fortalecimento do Estado deve começar por cada uma das entidades públicas que o compõem, mediante a compreensão das diferentes instituições formais e informais existentes em cada uma delas, assim como também dos mecanismos de cumprimento existentes das regras. Só compreendendo cada instituição dentro do respectivo contexto cultural, é possível direcionar acertadamente o desenvolvimento e a eficácia das atuações estatais.

Assim, o presente trabalho analisará o papel das instituições no progresso ou no estancamento das sociedades, enfatizando a importância de reconhecer as limitações históricas existentes em cada sociedade e em cada instituição, com a finalidade de melhorar a efetividade das políticas públicas e das ações estatais.

Em culturas latinas tem sido bastante comum o aumento do poder da lei e, por consequência, mantém-se a esperança de que, reformando as leis, os problemas são solucionados, quando, na verdade, a solução não é tão simples e demanda um esforço maior, em longo prazo, direcionado a mudar limitações culturais e reforçar os mecanismos de cumprimento das regras.

Dessa forma, no primeiro capítulo será analisado o conceito de instituição, no segundo será feita uma curta retomada da Revolução Americana, da Revolu- 
ção Francesa e do Caso Latino-Americano, com a finalidade de mostrar como as mudanças nas leis formais não são suficientes para criar instituições que promovam o bem-estar da sociedade. E por fim, no terceiro, uma tentativa de estabelecer parâmetros básicos e gerais que as instituições públicas deveriam cumprir para conseguir maior efetividade dentro da sociedade em que se desenvolvem.

\section{As instituições}

Segundo Chantal Mouffe, as democracias modernas não têm uma unidade substancial. Rawls concorda com o autor, ao afirmar que "[... ] temos de abandonar a esperança de uma comunidade política, se por tal comunidade entendermos uma sociedade política unida pela afirmação de uma doutrina geral e abrangente."

A mesma autora, citando Bobbio, afirma que ele:

[...] insiste em que devemos ser realistas e abandonar a esperança de uma "verdadeira democracia", de uma sociedade perfeitamente conciliada, de um consenso perfeito. A democracia moderna, insiste, tem de resolver o problema do pluralismo, o que implica que é inevitável uma forma qualquer de desacordo. O consenso é necessário, mas apenas no que diz respeito às regras do jogo. [...] Ou seja, devemos passar da democratização do Estado para a democratização da sociedade; tarefa consistente em lutar contra o poder autocrático sob todas as suas formas, a fim de invadir todos os espaços ainda ocupados por centros de poder não democráticos. Para Bobbio, a democratização da sociedade exige a transformação de todas as instituições.

Mas o que são as instituições? Como podem ser transformadas? Como se democratiza uma sociedade? Segundo North, ${ }^{3}$ as instituições são as regras do jogo numa sociedade, são as limitações idealizadas pelo homem que permitem a interação humana ao reduzir as incertezas e proporcionar uma estrutura à vida diária.

2 MOUFFE, Chantal. O regresso do político. Lisboa: Gradiva, 1996. p. 74.

3 Douglass North recebeu o premio Nobel em Ciências Econômicas em 1993 pela sua pesquisa em historia econômica a partir da aplicação de técnicas quantitativas para explicar os câmbios econômicos e institucionais. 
Dessa forma, o jogo vai estar determinado pelas normas formais, pelas normas informais e o tipo e pela eficácia da obrigatoriedade do cumprimento das regras. ${ }^{4}$

A principal função das instituições na sociedade é reduzir as incertezas, estabelecendo uma estrutura estável, mas não necessariamente eficiente da interação humana. No entanto, a estabilidade das instituições não contradiz o fato de que estejam mudando permanentemente. ${ }^{5}$ É importante ressaltar aqui que as instituições não procuram ser eficientes socialmente, elas são feitas para servir os interesses de quem tem poder de negociação para formular as regras, especialmente no caso das regras formais. ${ }^{6}$

Esse fato ficou claro com Kelsen na Teoria Pura do Direito, a qual "Procura responder a questão: o que é e como é o Direito? Mas já não lhe importa a questão de saber como deve ser o direito, ou como deve ele ser feito". Para Kelsen, os procedimentos são importantes, já que permitem alcançar acordos dentro de grupos em que não é possível uma vontade única e homogênea, e é por isso que “[...] apresenta os partidos e o parlamento como instrumentos necessários à formação da vontade do Estado." Dessa forma,

[...] qualquer decisão nunca será total e a coerência social só será atingida a custa da repressão de algo que se nega. É neste sentido que todo o consenso, que qualquer sistema de regras objetivo e diferenciado implica, como sua possibilidade mais essencial, uma dimensão coerciva. ${ }^{9}$

Nesse mesmo sentido se dirige a crítica de Jacques Derrida:

Ora, a operação de fundar, inaugurar, justificar o direito, fazer a lei, consistira num golpe de força, numa violência

${ }_{4}$ NORTH, Douglass C. Instituciones, cambio institucional y desempeño económico. Tradução de Agustín Bárcena. México: Fondo de Cultura Económica, 2006. p. 13-14.

5 NORTH, Douglass C. Instituciones, cambio institucional y desempeño económico. Tradução de Agustin Bárcena. México: Fondo de Cultura Económica, 2006. p. 16.

6 NORTH, Douglass C. Instituciones, cambio institucional y desempeño económico. Tradução de Agustin Bárcena. México: Fondo de Cultura Económica, 2006. p. 29.

7 KELSEN, Hans. Teoria pura do direito. Tradução de João Baptista Machado; Revisão para a edição brasileira: Silvana Vieira. São Paulo: M. Fontes. 1987. p. 1.

8 MOUFFE, Chantal. O regresso do político. Lisboa: Gradiva. 1996. p. 172.

9 MOUFFE, Chantal. O regresso do político. Lisboa: Gradiva. 1996. p. 188. 
performativa e, portanto interpretativa que, nela mesma, não é nem justa nem injusta, e que nenhuma justiça, nenhum direito prévio e anteriormente fundador, nenhuma função pré-existente, por definição, poderia nem garantir nem contradizer nem invalidar. ${ }^{10}[\ldots]$ Já que a origem da autoridade, a fundação ou o fundamento, a instauração da lei não podem, por definição, apoiar-se finalmente senão sobre elas mesmas, elas mesmas são uma violência sem fundamento. O que não quer dizer que sejam injustas em si, no sentido de "ilegais" ou "ilegítimas". Elas não são nem legais nem ilegais em seu momento fundador. Elas excedem a oposição do fundado ao não - fundado, como de todo fundacionismo ou todo antifundacionismo. ${ }^{11}$

Em nossa concepção, as incertezas do mundo obrigam os homens a procurarem ordem para possibilitar a vida em comunidade e o crescimento econômico em longo prazo, mediante a existência de direitos de propriedade claramente identificados. Assim, o fundamento principal para a instauração de leis numa sociedade é a necessidade de ordem, mas devido à impossibilidade de contar com uma ordem política consensual unânime, a coerção e a força são necessárias para sua conservação.

Aqui concordamos com Chantal Mouffe, quando afirma que as democracias plurais modernas bem ordenadas não podem prescindir da dominação e da violência, mas, por isso, é necessário estabelecer um conjunto de instituições que permita que esta violência seja limitada e contestada. ${ }^{12}$ Em nossa opinião, as entidades públicas não só devem ter uma competência muito bem delimitada, como também devem contar com mecanismos que permitam a todos os cidadãos interessados ou afetados expressarem suas opiniões e interesses para que sejam escutados e claramente contestados pela entidade pública.

Como é evidente, as instituições são uma criação humana, evoluem e são alteradas por humanos, afetando o desempenho da economia e da sociedade, em

${ }^{10}$ DERRIDA, Jacques. Forca de lei: o fundamento místico da autoridade. Tradução Leyla Perrone-Moises. São Paulo: M. Fontes. 2007. p. 24.

${ }^{11}$ DERRIDA, Jacques. Forca de lei: o fundamento místico da autoridade. Tradução Leyla Perrone-Moises. São Paulo: M. Fontes. 2007. p. 26.

${ }^{12}$ MOUFFE, Chantal. The democratic paradox. Essex: Verso, 2000. p. 22. 
geral. ${ }^{13}$ Então, assumindo que as instituições e as normas são necessárias para viver em comunidade, com um mínimo de estabilidade e ordem, a pergunta é: como criar instituições que promovam o bem-estar geral da população? Ou melhor, se as instituições são criação humana, por que existem desigualdade e pobreza em nosso mundo? E também, por que existem diferenças tão grandes entre países ou governos democráticos que, em princípio, contam formalmente com as mesmas instituições? North dá uma possível resposta a essa questão quando afirma:

Aunque las normas formales pueden cambiar de la noche a la mañana como resultado de decisiones políticas o judiciales, las limitaciones informales encajadas en costumbres, tradiciones y códigos de conducta son mucho más resistentes o impenetrables a las políticas deliberadas. Estas limitaciones culturales no solamente conectan el pasado con el presente $y$ el futuro, sino que nos proporcionan una clave para explicar la senda del cambio histórico. ${ }^{14}$

No livro "Da Revolução", Hannah Arendt também chega a uma conclusão similar ao comparar a constituição norte-americana com as da Europa continental, afirmando:

[...] (existe uma) enorme diferença, em poder e qualidade, entre uma constituição imposta a um povo por um governo, e uma constituição através da qual um povo constitui o seu próprio governo. As constituições dos especialistas, sob as quais Europa passou a viver após a Primeira Guerra Mundial, estavam todas elas baseadas, em grande parte, na Constituição americana, e, julgadas pelo que eram, deveriam ter funcionado muito bem. No entanto, a desconfiança que elas sempre suscitaram nas pessoas que viviam sob sua tutela é um tema que ficou amplamente documentado na História, como também o fato de que, quinze anos após a queda do governo monárquico no continente europeu, mais da metade de Europa vivia sob o jugo de alguma forma de tirania [...]. Pois a carência de poder e a concomitante falta de autoridade foram a maldição do governo constitucional em quase todos os países europeus, desde a abolição das monarquias absolutas, e as quatorze constituições da França,

\footnotetext{
${ }^{13}$ NORTH, Douglass C. Instituciones, cambio institucional y desempeño económico. Tradução de Agustin Bárcena. México: Fondo de Cultura Economica, 2006. p. 16.

${ }^{14}$ NORTH, Douglass C. Instituciones, cambio institucional y desempeño económico. Tradução de Agustin Bárcena. México: Fondo de Cultura Economica, 2006. p. 17.
} 
entre 1789 e 1875, fizeram com que a própria palavra se tornasse motivo de zombaria, e isso muito antes da chuva de constituições no período pós- guerra do século XX. ${ }^{15}$

A respeito disso, William Riker $^{16}$ se questiona se a estrutura constitucional origina uma condição política e um estado de opinião pública, ou bem a condição pública ou a condição política ou um estado de opinião pública causam a estrutura constitucional? Ele responde que, à primeira vista, isso parece ser o problema da galinha e o ovo, no qual, não existe direção causal; mas ele acredita que quase sempre existe uma causa e as formas constitucionais são tipicamente derivativas. Assim, para ele, é muito provável que a opinião pública crie uma estrutura constitucional e, em poucas vezes, aconteça o contrário. Como Rousseau afirmou, ao final das contas, a lei é o que está escrito nos corações das pessoas; isso é a única coisa que importa.

A história nos pode mostrar que as limitações culturais não mudam imediatamente com as alterações das regras formais, as quais criam uma tensão entre regras formais e regras informais, fazendo-as incongruentes, o que não só debilita o Estado, mas também impede e deslegitima sua atuação ante a sociedade.

A respeito disso, North chama "via da dependência” o fato de que a história importa, já que não podemos compreender as escolhas do presente sem compreendermos a evolução das instituições das nossas sociedades. Isso ocorre porque, ainda que as regras possam ser as mesmas, os mecanismos de cumprimento obrigatório, a forma em que se exerce a obrigatoriedade, as normas de conduta e os modelos subjetivos dos atores não o são. ${ }^{17}$

${ }^{15}$ ARENDT, Hannah. Da revolução. Tradução: Fernando Dídimo Vieira; Revisão da tradução: Navarro de Toledo. Brasília: Ática; Universidade de Brasília. 1988. p. 116-117.

${ }^{16}$ RIKER, William H. Comments on Vincent Ostrom's Paper, Public Choice, Local? v. 27, n. ?, p.13-15, 1976 apud. NORTH, Douglass C. Instituciones, cambio institucional y desempeño económico. Tradução de Agustin Bárcena. México: Fondo de Cultura Economica. 2006. p. 83.

${ }^{17}$ RIKER, William H. Comments on Vincent Ostrom's Paper, Public Choice, Local? v. 27, n.?, p. 13-15, 1976 apud. NORTH, Douglass C. Instituciones, cambio institucional y desempeño económico. Tradução de Agustin Bárcena. México: Fondo de Cultura Economica. 2006. p. 131-132. 


\section{A via de dependência histórica}

Um exemplo claro da dependência histórica das culturas pode se encontrar nas revoluções do século XVIII e XIX, iniciando com a Revolução Norte-americana, continuando com a Revolução Francesa e finalizando com o Caso Latino-americano, no qual a existência de diferentes pautas institucionais gerou resultados ideológicos radicalmente diferentes, que condicionaram o desenvolvimento social e econômico dos países. A respeito dessa questão, Hannah Arent assinala:

Do ponto de vista histórico, a diferença mais obvia e mais decisiva entre as Revoluções Americana e Francesa consistiu em que a herança histórica da Revolução Americana foi a "monarquia limitada", e a da Revolução Francesa, um absolutismo que aparentemente remontava aos primeiros séculos do Império Romano. De fato, nada parece mais natural do que uma revolução ser predeterminada pelo tipo de governo que ela baniu; nada por tanto, parece mais plausível do que explicar o novo absoluto, o absoluto da revolução, pela monarquia absoluta que o precedera, e concluir que, quanto mais absoluto o governo, tanto mais absoluta será a revolução que o substituir. ${ }^{18}$

\subsection{A revolução norte-americana}

Para compreender a Revolução Norte-Americana, é importante compreender alguns antecedentes do regime político constitucional da Inglaterra, razão pela qual analisaremos na sequência alguns pontos.

O poder político na Inglaterra, desde o século XVII, encontrava-se compartilhado entre o monarca e um parlamento que depois da Revolução de 1688-89, converteu-se em soberano. Assim, o regime político constitucional da Inglaterra, em contraste com o que existia no continente europeu, era de um absolutismo moderado, o qual tem sua origem na Carta Magna de $1215 .{ }^{19}$

\footnotetext{
${ }^{18}$ ARENDT, Hannah. Da revolução. Tradução: Fernando Dídimo Vieira; Revisão da tradução: Navarro de Toledo. Brasília,DF : Ática. Universidade de Brasília. 1988. p. 124.

${ }^{19}$ BREWER-CARÍAS, Allan. Reflexiones sobre la revolución norteamericana (1776), la revolución francesa (1789) y la revolución hispanoamericana (1810 - 1830) y sus aportes al constitucionalismo moderno. 2.ed. ampl. Bogotá: Universidad Externado de Colombia; Editorial Jurídica Venezolana, 2008. p. 30. (Derecho Administrativo, n. 2).
} 
Os antecedentes do parlamento se remontam ao século XIII, desde quando se tinha imposto o costume de que, em casos graves, o rei devia consultar representantes da nobreza e das comunidades mediante a sua convocatória, com o fim de conseguir a aceitação de novos impostos e conhecer o estado do reino. Assim, a Assembleia foi desenvolvendo progressivamente sua própria força, e lentamente começaria a apoderar-se de privilégios e prerrogativas reais, como o direito de investir ao rei, desde a coroação de Enrique de Lancaster em 1399. ${ }^{20}$

A Guerra Civil de 1642, que durou 18 anos, em que houve o enfrentamento entre parlamentaristas e realistas, conseguiu impedir o estabelecimento de monarquias absolutas, com a perpetuação do poder do Parlamento sobre o rei, e o estabelecimento do princípio de supremacia da lei. ${ }^{21}$

Ainda assim, o sistema jurídico inglês, desde antes do século XVII, organizou-se a partir da ideia da Common Law como lei fundamental, já que o direito e a razão comum faziam parte de uma lei superior que obriga tanto ao Parlamento como as cortes ordinárias e ao rei, o que permitiu que a Carta Magna tivesse sido interpretada como uma lei fundamental do reino e aplicada pelos tribunais como meio de proteção de direitos naturais das pessoas. ${ }^{22}$

Dessa forma, o Parlamento inglês proporcionou o início de um governo representativo e reforçou a seguridade dos direitos de propriedade, assim como

${ }^{20}$ BREWER-CARÍAS, Allan. Reflexiones sobre la revolución norteamericana (1776), la revolución francesa (1789) y la revolución hispanoamericana (1810 - 1830) y sus aportes al constitucionalismo moderno. 2.ed. ampl. Bogotá: Universidad Externado de Colombia;. Editorial Jurídica Venezolana, 2008. p. 39. (Derecho Administrativo, n. 2).

${ }^{21}$ BREWER-CARÍAS, Allan. Reflexiones sobre la revolución norteamericana (1776), la revolución francesa (1789) y la revolución hispanoamericana (1810 - 1830) y sus aportes al constitucionalismo moderno. 2.ed. ampl. Bogotá: Universidad Externado de Colombia; Editorial Jurídica Venezolana, 2008. p. 47-48. (Derecho Administrativo, n. 2).

22 BREWER-CARÍAS, Allan. Reflexiones sobre la revolución norteamericana (1776), la revolución francesa (1789) y la revolución hispanoamericana $(1810$ - 1830) y sus aportes al constitucionalismo moderno. 2.ed. ampl. Bogotá: Universidad Externado de Colombia; Editorial Jurídica Venezolana, 2008. p. 48-53. (Derecho Administrativo, n. 2). 
a existência de um sistema judicial imparcial mais eficaz. ${ }^{23}$ Assim, para o século XVIII, o Império Britânico tinha numerosos níveis de governo, cada um deles com uma esfera bem definida de autoridade..$^{24}$

Neste contexto, a colonização inglesa da América do Norte, ao contrário da colonização espanhola na América do Sul, não teve uma política centralizadora. Desde o início, a Coroa permitiu a existência de governos locais pelos colonos. A maioria dos colonos fugia de perseguições e conflitos existentes na Inglaterra, razão pela qual, sem ter concessões nem direitos de qualquer classe, eles tiveram a necessidade de fixar suas próprias regras e estabelecer pactos para comprometerem-se a permanecer juntos e obedecer às regras para conseguir o bem-estar de todos. ${ }^{25}$

Em decorrência disso, em 1750, todas as colônias tinham uma ampla autonomia com governos autônomos e assembleias com duas câmaras, onde se resolviam os assuntos locais, e sem mecanismos centralizadores da administração colonial. North descreve essa etapa assim:

Hasta el final de Guerra de los Siete Años, en 1763, la intervención británica en América del Norte se limitaba a la provisión de los bienes públicos vigentes en todo el imperio, sobre todo la seguridad y el comercio exterior. Las asambleas coloniales, que trabajaban con el gobernador imperial, disfrutaban de una amplia autoridad sobre los bienes públicos locales, los derechos de propiedad, la libertad religiosa y la aplicación de contratos, sujeta a ciertas restricciones determinadas por el derecho británico. [...] Diversos cambios producidos en la política imperial británica luego de 1763 amenazaron ese sistema. Dos de ellos tuvieron una influencia critica. En primer lugar, aunque la guerra elimino la amenaza francesa, se pago un enorme costo económico que dejo a Gran Bretaña con la deuda mas grande de su historia. Los británicos acudieron

${ }^{23}$ NORTH, Douglass C. Instituciones, cambio institucional y desempeño económico. Tradução de Agustin Bárcena. México: Fondo de Cultura Economica. 2006, p. 148.

${ }^{24}$ NORTH, Douglass C. Para entender el proceso de cambio económico. Tradução Horacio Pons. Bogotá: Norma. 2007, p. 158.

${ }^{25}$ BREWER-CARÍAS, Allan. Reflexiones sobre la revolución norteamericana (1776), la revolución francesa (1789) y la revolución hispanoamericana (1810 - 1830) y sus aportes al constitucionalismo moderno. 2. ed. ampl. Bogotá: Universidad Externado de Colombia; Jurídica Venezolana, 2008. p. 64-65. (Derecho Administrativo, n. 2). 
a las colonias para financiar una parte de la deuda. En segundo lugar, la derrota francesa produjo una gran modificación en el imperio. [...] Estos cambios indujeron a muchos norteamericanos a deducir que Gran Bretaña ya no respetaría los principios del federalismo dentro del imperio. $^{26}$

Por isso, quando o Parlamento inglês estabeleceu diversos impostos sobre os produtos coloniais, as colônias americanas rejeitaram tal imposição, com base no direito tradicional estabelecido desde a Idade Média de não estar sujeito a impostos sem prévio consentimento.

É inegável a singular boa sorte da Revolução americana. Ela ocorreu em um país que desconhecia completamente a difícil situação da miséria popular, e entre um povo que tinha uma larga experiência de auto governo; certamente, uma de suas maiores graças foi a revolução ter sido conseqüência do conflito com uma "monarquia limitada.".

A Declaração de Direitos de Virginia de 1776 não utilizou a “Common Law” nem os direitos dos ingleses, como a Carta Magna ou o "Bill of Rights”, senão simplesmente deriva os direitos das leis da natureza humana, da razão e Deus, o que constitui o primeiro documento na história constitucional que legitima jurídica e politicamente o autogoverno com base nos direitos naturais do homem, evidenciando-se uma forte influência das ideias do Locke. ${ }^{28}$

Depois da vitória norte-americana em 1783, foi evidente a necessidade de estabelecer um poder central para a qual foi convocada uma Convenção Federal que produziu em 1787, a Declaração pelo Congresso, da Constituição dos Estados Unidos como resultado de uma série de compromissos políticos e sociais das

${ }^{26}$ NORTH, Douglass C. Para entender el proceso de cambio económico. Tradução Horacio Pons. Bogotá: Norma, 2007. p. 159 - 160.

${ }^{27}$ ARENDT, Hannah. Da revolução. Tradução: Fernando Dídimo Vieira; Revisão da tradução: Navarro de Toledo. Brasília: Ática; Universidade de Brasília, 1988. p. 125.

${ }^{28}$ BREWER-CARÍAS, Allan. Reflexiones sobre la revolución norteamericana (1776), la revolución francesa (1789) y la revolución hispanoamericana (1810 - 1830) y sus aportes al constitucionalismo moderno. 2. ed. ampl. Bogotá: Universidad Externado de Colombia; Jurídica Venezolana, 2008. p. 74. (Derecho Administrativo, n. 2). 
colônias independentes, estabelecendo-se um sistema de separação de poderes, equilibrados e controlados entre si. ${ }^{29}$

Las controversias abundaron durante la época de los Artículos de la Confederación y la firma de la Constitución, pero los fundamentos de estabilidad de las reglas políticas y económicas se trasladaron de las cartas coloniales al periodo de la independencia. [...] Los debates entablados durante esta época sirvieron para suscitar nuevas creencias compartidas sobre los límites impuestos a la autoridad política federal y la importancia de los derechos ciudadanos y la autonomía estatal. $^{30}$

\subsection{A revolução francesa}

A monarquia absoluta na Franca tem sua origem em 1223, com a morte de Felipe. Segundo Augusto, que impôs a sucessão hereditária ao trono com a ideia de que ninguém outorgava poderes ao rei, ele simplesmente os tinha pela graça de Deus; estabelecendo-se assim o princípio da inviolabilidade do monarca, baseado no fato de que seu poder era proveniente de Deus. Daí que seu poder fosse consagrado pelo Papa. Dessa forma, o rei se tornou fonte de toda justiça, legislação e governo. $^{31}$

Desde o Antigo Regime Medieval, existia uma estrutura social aristocrática, fundada tanto no privilégio do nascimento como da riqueza territorial, na qual existiam três ordens ou estados: o primeiro era do rei, o segundo, do clero e da nobreza, como classes privilegiadas e, em consequência, no terceiro estado se

\footnotetext{
${ }^{29}$ BREWER-CARÍAS, Allan. Reflexiones sobre la revolución norteamericana (1776), la revolución francesa (1789) y la revolución hispanoamericana $(1810$ - 1830) y sus aportes al constitucionalismo moderno. 2.ed.ampl. Bogotá: Universidad Externado de Colombia; Jurídica Venezolana, 2008. p. 80. (Derecho Administrativo, n. 2).

${ }^{30}$ NORTH, Douglass C. Para entender el proceso de cambio económico. Tradução Horacio Pons. Bogotá: Norma, 2007. p. 161.

${ }^{31}$ BREWER-CARÍAS, Allan. Reflexiones sobre la revolución norteamericana (1776), la revolución francesa (1789) y la revolución hispanoamericana (1810 - 1830) y sus aportes al constitucionalismo moderno. 2. ed. ampl. Bogotá: Universidad Externado de Colombia; Jurídica Venezolana, 2008. p. 125-126. (Derecho Administrativo, n. 2).
} 
encontrava o resto da população, incluindo a burguesia (comerciantes e artesãos) e a aristocracia (funcionários de alto cargo). Adicionalmente, o sistema econômico (mercantilismo) também era centralizado e estatalista, já que o rei intervinha e controlava a economia por meio de concessões outorgadas só às classes privilegiadas (nobres e clero), o que radicalizava ainda mais as diferenças entre os estados ou ordens. ${ }^{32}$

Devido à complexidade do reino, desenvolveram-se instituições chamadas "intendências", nas quais, por delegação direita do rei, os intendentes estavam encarregados do governo, da administração e da justiça. Paralelamente conformaram-se também cortes de justiça, chamados Parlaments, como tribunais permanentes de apelação. Na monarquia absoluta, o poder supremo de fazer as leis era do rei, razão pela qual é inconcebível a existência de uma constituição rígida. ${ }^{33}$

No momento da Revolução, existiam trinta e dois intendentes, que administravam territorialmente o reino como funcionários todo-poderosos, já que tinham várias competências, eram órgãos de administração de justiça em última instância, participavam em juízos e vigiavam aos demais magistrados, eram órgãos de polícia, dirigiam a administração em geral, controlavam o comércio, a agricultura, a indústria, e estavam também encarregados da arrecadação dos impostos. ${ }^{34}$

Os Parlaments pelo costume tinham adquirido ao longo dos séculos o direito de registro das leis ou editos que ditava o monarca, como um requisito para

${ }^{32}$ BREWER-CARÍAS, Allan. Reflexiones sobre la revolución norteamericana (1776), la revolución francesa (1789) y la revolución hispanoamericana (1810 - 1830) y sus aportes al constitucionalismo moderno. 2. ed. ampl. Bogotá: Universidad Externado de Colombia; Jurídica Venezolana, 2008. p. 122-125. (Derecho Administrativo, n. 2).

${ }^{33}$ BREWER-CARÍAS, Allan. Reflexiones sobre la revolución norteamericana (1776), la revolución francesa (1789) y la revolución hispanoamericana (1810 - 1830) y sus aportes al constitucionalismo moderno. 2. ed. ampl. Bogotá: Universidad Externado de Colombia; Jurídica Venezolana, 2008. p. 127-128. (Derecho Administrativo, n. 2).

${ }^{34}$ BREWER-CARÍAS, Allan. Reflexiones sobre la revolución norteamericana (1776), la revolución francesa (1789) y la revolución hispanoamericana (1810 - 1830) y sus aportes al constitucionalismo moderno. 2. ed. ampl. Bogotá: Universidad Externado de Colombia; Jurídica Venezolana, 2008. p. 132-133. (Derecho Administrativo, n. 2). 
sua execução, o que era considerado pelo rei como uma concessão real. A respeito disso, Tocqueville explicava:

[...] Pero cuando al fin expresaba su voluntad (el rey), todo volvía al silencio y a la obediencia, porque los Magistrados reconocían que no eran más que los primeros funcionarios del príncipe y sus representantes, encargados de ilustrarle y no de coartarle. ${ }^{35}$

Aqui, é importante levar em consideração que os magistrados do Parlaments, por uma evolução peculiar, tinham direitos hereditários sobre o cargo, razão pela qual os cargos podiam comprar-se e também se converteu em costume a obrigatoriedade de pagar em preço ou em espécie aos magistrados para obter justiça. Por isso, os Parlaments terminariam agindo contra a monarquia, já que se consideravam independentes ao não ter que depender do rei, mas, uma vez estabelecida a Revolução, os Parlaments foram abolidos pelo États Généraux, pois representavam uma aristocracia corrupta e ineficiente. ${ }^{36}$

Ainda assim, o papel dos Parlament foi fundamental para o início da Revolução, quando em 1787 o Parlament de Paris começou a pedir justificações sobre editos que estabeleciam maiores impostos para fazer frente à crise fiscal do reino, estabelecendo pela primeira vez que só a nação tinha o direito a conhecer novos impostos, solicitando em consequência a convocatória dos Etats Généraux. Depois de dois anos de intensos confrontos entre o Parlament e o rei, este se vê obrigado a convocar os États Généraux depois de 175 anos de inatividade, e aí se deu o início da Revolução Francesa. ${ }^{37}$

\footnotetext{
${ }^{35}$ BREWER-CARÍAS, Allan. Reflexiones sobre la revolución norteamericana (1776), la revolución francesa (1789) y la revolución hispanoamericana (1810 - 1830) y sus aportes al constitucionalismo moderno. 2. ed. ampl. Bogotá: Universidad Externado de Colombia; Jurídica Venezolana, 2008. p. 139. (Derecho Administrativo, n. 2).

${ }^{36}$ BREWER-CARÍAS, Allan. Reflexiones sobre la revolución norteamericana (1776), la revolución francesa (1789) y la revolución hispanoamericana (1810 - 1830) y sus aportes al constitucionalismo moderno. 2. ed. ampl. Bogotá: Universidad Externado de Colombia; Jurídica Venezolana, 2008. p. 140-142. (Derecho Administrativo, n. 2).

${ }^{37}$ BREWER-CARÍAS, Allan. Reflexiones sobre la revolución norteamericana (1776), la revolución francesa (1789) y la revolución hispanoamericana (1810 - 1830) y sus aportes al constitucionalismo moderno. 2. ed. ampl. Bogotá: Universidad Externado de Colombia; Jurídica Venezolana, 2008. p.155-160. (Derecho Administrativo, n. 2).
} 
Devido à inatividade dos États Généraux, ninguém tinha claridade sobre as regras para seu funcionamento, o que gerou muita desordem e tensões para determinar quem controlaria as discussões e as votações, e quem terminou controlando foi a burguesia, que, afinal, foi quem fez a revolução. ${ }^{38}$

Quando a Assembleia começou a ditar decretos tirando o poder do rei, o monarca derrogou os decretos e tentou a dissolução da Assembleia, frente a qual os deputados do Tiers État (membros da burguesia) com o apoio popular impuseram ao rei o novo regime, instalando a Assembleia de maneira permanente a partir de agosto de 1789. A Assembleia em poucos meses fez uma revolução jurídica, mudando todos os instrumentos que regiam a monarquia, configurando um novo Estado, ${ }^{39}$ baseando-se no princípio da supremacia da lei e do legislador como novo representante, novo poderoso da Nação.

[...] assim, a concepção de Rousseau acerca de uma nova vontade geral, inspirando e dirigindo a nação, como se ela não fosse mais formada de uma multidão, mas de uma só pessoa, tornara-se axiomática para todas as facções e partidos da Revolução Francesa, por ser ela, na verdade, o substituto teórico da vontade soberana de um monarca absoluto. $^{40}$

A Revolução originou as guerras das monarquias europeias contra a França, que se encontrava ameaçada em todas suas fronteiras, portanto, a Revolução, além de consolidar-se internamente, teve que proteger-se externamente. Assim, o terror político e revolucionário se apoderou da França e o caos se generalizou, sobretudo pela coalizão estrangeira que se formou contra a França. Nesse cenário, Napoleão Bonaparte realizou um golpe de estado e impôs uma Constituição autoritária, re-

${ }^{38}$ BREWER-CARÍAS, Allan. Reflexiones sobre la revolución norteamericana (1776), la revolución francesa (1789) y la revolución hispanoamericana $(1810$ - 1830) y sus aportes al constitucionalismo moderno. 2. ed. ampl. Bogotá: Universidad Externado de Colombia; Jurídica Venezolana, 2008. p. 160-165. (Derecho Administrativo, n. 2).

${ }^{39}$ BREWER-CARÍAS, Allan. Reflexiones sobre la revolución norteamericana (1776), la revolución francesa (1789) y la revolución hispanoamericana $(1810$ - 1830) y sus aportes al constitucionalismo moderno. 2. ed. ampl. Bogotá: Universidad Externado de Colombia; Jurídica Venezolana, 2008. p. 166-171. (Derecho Administrativo, n. 2).

${ }^{40}$ ARENDT, Hannah. Da revolução. Tradução: Fernando Dídimo Vieira. Revisão da tradução: Navarro de Toledo. Brasília: Ática; Universidade de Brasília, 1988. p. 125. 
organizando centralizadamente a justiça, a administração e a economia, fazendo-se designar cônsul vitalício (1802) e depois Imperador dos franceses (1804). ${ }^{41} \mathrm{Em}$ consequência, a Declaração de Direitos do Homem de 1789 só pode considerar-se como um texto histórico, sem consequências jurídicas precisas. ${ }^{42}$

A história constitucional da França, onde, mesmo durante a revolução, as constituições se sucediam umas às outras, enquanto aqueles que detinham o poder se mostravam incapazes de impor o cumprimento de qualquer das leis e decretos revolucionários, pode facilmente ser interpretada como uma crônica monótona que demonstra à sociedade, aquilo que devia ter sido obvio desde o início, ou seja, que a propalada vontade da multidão é por definição mutável e inconstante, e que uma estrutura construída sobre esse fundamento é como se estivesse sobre areia movediça. ${ }^{43}$

\subsection{0 caso latino-americano}

Tanto a coroa espanhola como a coroa portuguesa eram monarquias absolutas que apresentavam quase as mesmas características que a coroa francesa, centralização de poder por parte do rei, sociedade estratificada e um sistema econômico mercantilista, onde o objetivo principal foi a extração de metais preciosos. A Coroa outorgava privilégios monopolísticos exclusivos e o comércio estava limitado a uma pequena quantidade de portos. Assim, a política autoritária das coroas espanhola e portuguesa não permitiu o desenvolvimento do autogoverno nem de mercados competitivos. ${ }^{44}$

${ }^{41}$ BREWER-CARÍAS, Allan. Reflexiones sobre la revolución norteamericana (1776), la revolución francesa (1789) y la revolución hispanoamericana (1810 - 1830) y sus aportes al constitucionalismo moderno. 2. ed. ampl. Bogotá: Universidad Externado de Colombia; Jurídica Venezolana, 2008. p. 172-173. (Derecho Administrativo, n. 2).

${ }^{42}$ BREWER-CARÍAS, Allan. Reflexiones sobre la revolución norteamericana (1776), la revolución francesa (1789) y la revolución hispanoamericana (1810 - 1830) y sus aportes al constitucionalismo moderno. 2. ed. ampl. Bogotá: Universidad Externado de Colombia; Jurídica Venezolana, 2008. p. 174. (Derecho Administrativo, n. 2).

${ }^{43}$ ARENDT, Hannah. Da revolução. Tradução: Fernando Dídimo Vieira; Revisão da tradução: Navarro de Toledo. Brasília: Ática; Universidade de Brasília. 1988. p. 130.

${ }^{44}$ NORTH, Douglass C. Para entender el proceso de cambio económico. Tradução Horacio Pons. Bogotá: Norma, 2007.p. 163. 
Quando Napoleão encarcerou o Rei da Espanha em 1807, começaram movimentos de independência na América Latina, o que gerou a fragmentação das colônias em novas repúblicas, as quais, influenciadas pelas constituições dos Estados Unidos e da França, ${ }^{45}$ estabeleceram suas próprias, mas as consequências foram radicalmente diferentes.

Sin la herencia del auto-gobierno colonial y derechos de propiedad bien especificados, la independencia se desintegro en una violenta lucha entre grupos rivales por el control de la comunidad política y la economía. El resultado fue la captura de la comunidad política y su utilización como vehículo de intercambio personal en todos los mercados. En la mayor parte de Hispanoamérica, la victoria de uno de los grupos sobre sus rivales solo se logró al cabo de medio siglo de conflictos. El establecimiento del orden se convirtió en una meta por sí misma, la cual trajo consigo la creación y perpetuación de regímenes autoritarios: el fenómeno del "caudillismo" llegó a ser dominante. ${ }^{46}$

Na América Latina, os novos Estados não conseguiram estabelecer instituições republicanas, já que estas se chocavam com os fundamentos políticos da velha ordem, não existia um sistema compartilhado de crenças para o estabelecimento de uma ordem mínima, o que resultou na incapacidade estatal para fazer compromissos críveis e na instabilidade política. A constante instabilidade política na América Latina gerou a procura geral de ganhos em curto prazo, (pela falta de garantias sobre os direitos de propriedade e liberdade individual) autoritarismo político, distribuição adversa de renda e uma provisão ineficiente de bens públicos com um lento crescimento econômico. ${ }^{47}$

Adicionalmente uma das consequências do controle político centralizado é que limita as opções ou as alternativas de produção de bens e serviços que uma so-

${ }^{45}$ BREWER-CARÍAS, Allan. Reflexiones sobre la revolución norteamericana (1776), la revolución francesa (1789) y la revolución hispanoamericana (1810 - 1830) y sus aportes al constitucionalismo moderno. 2. ed. ampl. Bogotá: Universidad Externado de Colombia; Jurídica Venezolana, 2008. p. 202. (Derecho Administrativo, n. 2).

${ }^{46}$ NORTH, Douglass C. Para entender el proceso de cambio económico. Tradução Horacio Pons. Bogotá: Norma, 2007. p. 163-164.

${ }^{47}$ NORTH, Douglass C. Para entender el proceso de cambio económico. Tradução Horacio Pons. Bogotá: Norma, 2007. p. 164-165. 
ciedade pode desenvolver em longo prazo. Por isso, a falta de um controle político e econômico centralizado em países como Inglaterra e Estados Unidos gerou um ambiente propício para o desenvolvimento econômico e para a liberdade humana, já que a diversidade de opções procuradas aumenta a probabilidade de sucesso e de crescimento econômico. ${ }^{48}$

As políticas autoritárias em países latino-americanos estão bem documentadas por diferentes autores; um exemplo pode ser encontrado em John Coatsworth que, ao descrever as instituições mexicanas do século XIX, comenta:

La naturaleza intervencionista y generalmente arbitraria del medio institucional obligó a todas las empresas, urbanas o rurales, a operar de un modo altamente politizado, valiéndose de redes de parentesco, influencia política y prestigio familiar para ganar un acceso privilegiado a los créditos subsidiados, para valerse de estratagemas y ventajas para conseguir mano de obra, para cobrar deudas, o hacer cumplir contratos, para evadir impuestos o esquivar a los tribunales y para defender o afirmar tener títulos de tierras. El éxito o el fracaso en la arena económica dependían siempre de la relación del productor con las autoridades políticas - funcionarios locales para arreglar las cosas inmediatas y el gobierno central de la colonia para las interpretaciones favorables de la legislación así como su intervención en el nivel local donde la situación lo exigía. La pequeña empresa excluida del sistema de privilegios corporados y de los favores políticos, se vio forzada a operar en un estado permanente de semiclandestinidad, siempre al margen de la ley, a merced de funcionarios de segundo orden, nunca a salvo de actos arbitrarios y nunca protegida contra los derechos de los más poderosos. ${ }^{49}$

Com relação ao caso colombiano, Ana Maria Bejarano, opinando sobre a efetividade da Constituição colombiana de 1991, diz:

\footnotetext{
${ }^{48}$ NORTH, Douglass C. Para entender el proceso de cambio económico. Tradución Horacio Pons. Bogotá: Norma, 2007. p. 199.

${ }^{49}$ COATSWORTH, John. Obstacles to economic growth in nineteenth. American Historical Review, Mexico, v. 83, n.1, p.80-100, feb. 1978 apud NORTH, Douglass C. Instituciones, cambio institucional y desempeño económico. Tradução de Agustin Bárcena. México: [s.n.], 2006. p. 151.
} 
No basta con reformar la Constitución, eliminando las rigideces del régimen, haciéndolo más flexible, más amplio, más "democrático", hacía falta reconocer que detrás de la débil e incompleta democracia colombiana se escondía un Estado precario, incapaz de respaldar las instituciones típicas de la democracia, así como las libertades y los derechos que sirven de marco al desarrollo de la sociedad civil y, en parte como consecuencia de lo anterior, también se escondía una sociedad civil débil, fragmentada, en algún sentido "hobbesiana", atravesada por múltiples conflictos entre poderosos actores armados, entre ellos la guerrilla, los paramilitares y los ejércitos privados del narcotráfico.

Vale la pena tener presente que la ciudadanía, la participación y la representación, no dependen solamente de "la efectividad de una compleja red de relaciones legales", sino también de "organizaciones estatales dispuestas a y capaces de hacer valer los derechos afirmados en las leyes pertinentes" (O'Donell, 1994, p??). En buena medida, es posible afirmar que la Constitución de 1991 no ha producido los resultados que todos esperábamos debido a que no existe en Colombia un Estado capaz de respaldar y hacer cumplir (enforce) la norma constitucional. $^{50}$

No caso do Brasil, Luiz Roberto Barroso afirma:

A constatação inevitável, desconcertante, é que o Brasil chega à pós-modernidade sem ter conseguido ser liberal nem moderno. Herdeiros de uma tradição autoritária e populista, elitizada e excludente, seletiva entre amigos e inimigos - e não entre certo e errado, justo ou injusto -, mansa com os ricos e dura com os pobres, chegamos ao terceiro milênio atrasados e com pressa. ${ }^{51}$

Finalmente, com relação ao Caso Latino-Americano, North afirma o seguinte:

Lo esencial para el desempeño exitoso a largo plazo de las economías desarrolladas han sido, sin lugar a dudas, las normas informales profundamente arraigadas que limitan el grado de libertad de los actores políticos. [...] La creación

${ }^{50}$ BEJARANO, Ana María. La Constitución de 1991: un proyecto de construcción institucional. Hacia el rediseño del Estado. Bogotá: TM; Departamento Nacional de Planeación, 1999. p. 221.

${ }^{51}$ BARROSO, Luiz Roberto (Org.). Fundamentos teóricos e filosóficos do novo direito constitucional brasileiro. 3. ed. rev. Rio de Janeiro: Renovar, 2008. p. 52. 
de una comunidad política consensual estable lleva tiempo y la mera instauración de las reglas formales es una receta para la desilusión, por no decir el desastre. Como se dijo antes, luego de una independencia la mayoría de los países latinoamericanos sancionaron constituciones basadas sobre la norteamericana, pero con consecuencias radicalmente diferentes. Las comunidades politicas consensuales exitosas requieren de una serie de normas para limitar a los actores y su desarrollo no es rápido. Un proceso acumulativo de incremento de las aptitudes autóctonas, en el que la ayuda externa representada por la asistencia educacional, medica o de otro tipo se ocupe de forma explícita de transferir esas aptitudes al país en desarrollo, creara gradualmente el capital humano que es un prerrequisito necesario de una comunidad política consensual. Como es obvio, cualquier iniciativa deliberada para ampliar el capital humano de las economías de mal desempeño debe basarse en un comprensión explicita del patrimonio cultural de estas. ${ }^{52}$

\section{As instituições públicas}

Como afirmamos na introdução, na atualidade não existe dúvida sobre a necessidade e a importância do Estado para o desenvolvimento social e econômico da sociedade, mas isso implica a necessidade de formar entidades públicas que promovam o bem-estar geral da população, já que a captura do Estado por parte de interesses privados coloca em grave risco a governabilidade e a democracia necessárias para a estabilidade dos governos, tal como o aprecia Young, “[...] a justiça social significa eliminar a dominação e a opressão institucionalizadas." 53

Para Young, a justiça também deve se preocupar com as condições institucionais necessárias para o desenvolvimento e exercício das capacidades individuais, de comunicação e cooperação coletiva; porque são as estruturas e instituições sociais mais que a maldade individual que produzem as injustiças que caracterizam

\footnotetext{
${ }^{52}$ NORTH, Douglass C. Para entender el proceso de cambio económico. Tradução Horacio Pons. Bogotá: Norma, 2007. p. 233.

${ }^{53}$ YOUNG, I. M. 1990. p, 15 apud CAMBELL, Tom. La justicia: los principales debates contemporáneos. Barcelona: Gedisa, 2002. p. 204.
} 
boa parte da vida moderna. A maior parte das injustiças não surge das intenções de um indivíduo ou conjunto de indivíduos em particular, mas é consequência de disposições sociais que superam as intenções e o controle das pessoas individuais. ${ }^{54}$

De igual forma, o capítulo dois demonstrou como as alterações nas normas formais não são suficientes para gerar mudanças nas diferentes instituições de uma sociedade, já que as limitações informais ou culturais e a obrigatoriedade no cumprimento das regras não mudam tão facilmente, o que evidencia a necessidade de trabalhar em mecanismos que ajudem a criar uma estrutura de limitações informais que ajude na criação de condições apropriadas para o desenvolvimento social e econômico da sociedade, assim como também melhorar os controles e sua efetividade para o cumprimento das regras do jogo.

O problema principal aqui é que não existem fórmulas mágicas para a geração de políticas públicas exitosas, já que, num mundo de incertezas, ninguém pode ter a resposta correta; mas de maneira geral, podemos enumerar alguns parâmetros básicos que podem ajudar a melhorar, em longo prazo, o desempenho das entidades públicas.

Em primeiro lugar, é necessário reconhecer que o capital mais importante de toda entidade pública é seu capital humano. Assim, as entidades estatais devem investir permanentemente na capacitação do pessoal e para isso devem contar com um plano de capacitação integral que melhore os conhecimentos técnicos para o desempenho dos empregos, mas também capacitações grupais que gerem espaços de discussão entre os funcionários sobre temas como: os valores institucionais, a aplicabilidade de princípios constitucionais, as atividades diárias ou requisitos mínimos que devem ter os produtos ou serviços gerados pela entidade, com a finalidade de gerar um consenso mínimo ao interior das entidades sobre como gerar maior bem-estar à comunidade.

${ }^{54}$ YOUNG, I. M. 1990. p, 15. apud CAMBELL, Tom. La justicia. los principales debates contemporáneos. Barcelona: Gedisa, 2002. p. 205. 
Em nossa opinião, o consenso na sociedade é impossível devido à existência de crenças e valores diferentes que devem ser respeitados. Mas, nas entidades públicas, devem existir consenso e claridade para cada funcionário sobre a importância de cumprir com determinados princípios e valores no desenvolvimento das atividades em razão à necessidade de salvaguardar o interesse geral sobre o particular, é dizer, a necessidade de criar uma moralidade pública. Assim, cada funcionário deve ter claridade sobre como aplicar em suas atividades diárias princípios como a transparência, objetividade, interesse geral, efetividade, já que, para cada instituição, a interpretação de cada princípio muda e tem implicações diferentes.

Com relação à moralidade, Alasdair MacIntyre afirma que ela nasce como um conjunto de princípios da valoração e da ação humana, os quais são inseparáveis das práticas sociais e históricas que também definem as modalidades de uso. Detrás da moralidade se encontra o conceito de cultura, que é a explicação social da moralidade, e os dois permitem a convivência social.

[...] la moralidad no existe sino en conformaciones sociales reales o posibles, y lo que expresa, o puede expresar, coincide con sus formas insertadas socialmente. Estudiar cualquier tipo de moralidad abstrayendo sus principios y posteriormente estudiándolos separadamente de la práctica social por ellos informada, significa no entenderlos. ${ }^{55}$

A partir da sua definição da moralidade encarnada em uma cultura, MacIntyre afirmará que as instituições sociais neutras são impossíveis desde um ponto de vista moral, tendo em conta que o conhecimento moral está ligado à prática na sua configuração histórica e social. Ele define a prática como:

[...] son todas las actividades en cuyo interior los individuos no solo aprenden a perseguir algunos bienes, sino que también aprenden cómo transformar en juicios más adecuados las precedentes y aun provisionales nociones de aquellos mismos bienes, por medio de la crítica racional. De esta forma

\footnotetext{
${ }^{55}$ ALASDAIR, 1991 apud HERRERA, Gomez Manuel. Liberalismo versus comunitarismo, seis voces para un debate y una propuesta. Navarra: Garrigues Catedra Universidad de Navarra; Thomson Aranzadi, 2007. p. 122.
} 
la actividad interna a las prácticas es informada por un conocimiento teórico y práctico.

[...]

Aprender a ser bueno en el contexto de las practicas implica por tanto, aprender a como discriminar entre situaciones en las que uno esta, y situaciones en las que no es movido a la acción por el hecho de tener una buena razón. Y esto se aprende inicialmente por el hecho de que los otros nos dan buenas razones y nos critican cuando actuamos según las mismas. $^{56}$

Dessa forma, a racionalidade só é possível na sociedade porque, fora das práticas, os indivíduos estariam motivados por fatores emotivos e não teriam condições para dar uma razão clara sobre seu agir. Existem três características básicas da prática: a primeira é o reconhecimento de uma autoridade especialista da qual se deve aprender; a segunda é a educação das pessoas comprometidas com a prática, mediante a compreensão dos critérios objetivos pelos quais ela é regida, e, finalmente, a terceira trata sobre o desenvolvimento de um conjunto de virtudes intelectuais e morais indispensáveis para a adequada compreensão dos critérios e a adequada consecução dos fins internos. ${ }^{57}$

Los criterios que definen la práctica no son indiferentes respecto a las relaciones sociales: al contrario las cualifican, estableciendo una precisa organización (comunitaria) de las relaciones sociales y de las relaciones humanas en su interior. En consecuencia, la presencia de las virtudes es demandada con el fin de conservar el deber, la estabilidad y la seguridad de tales relaciones. En conclusión en la base de toda práctica existen esquemas coherentes y ordenados de representaciones, criterios de actividad y de relaciones, habilidades y virtudes. Comprometerse con una práctica equivale a insertarse en

\footnotetext{
${ }^{56}$ MACINTYRE, 1986 apud HERRERA, Gomez Manuel. Liberalismo versus comunitarismo, seis voces para un debate y una propuesta. Navarra: Garrigues Catedra Universidad de Navarra; Thomson Aranzadi, 2007. p. 130.

${ }^{57}$ HERRERA, Gomez Manuel. Liberalismo versus comunitarismo, seis voces para un debate y una propuesta. Navarra: Garrigues Catedra Universidad de Navarra; Thomson Aranzadi, 2007. p. 132.
} 
una forma de comunidad motivada en su interior [...] por la consecución de un bien común. ${ }^{58}$

Para MacIntyre, a prática exige uma específica reeducação das pessoas comprometidas com ela, o que vai ajudar a determinar critérios objetivos para a construção de uma concepção comum e racional do "bem”. A prática com os seus critérios se desenvolve no interior das instituições, criadas para a sua salvaguarda, estabelecendo as condições para sua existência e uma educação específica. Como consequência, dependendo dos valores e fins externos à pratica, esta será virtuosa ou será corrupta. ${ }^{59}$

[...] las virtudes son entendidas como aquellas disposiciones que no solo sugieren las practicas y nos permiten alcanzar sus valores internos, sino que también nos ayudan a la búsqueda del bien que nos interesa permitiéndonos superar los males, los peligros, las tentaciones y las distracciones que nos obstaculizan, y nos elaboran un conocimiento creciente de nosotros mismos $y$ del bien. ${ }^{60}$

Mas por outro lado, e ainda contando com práticas virtuosas dentro das entidades, é possível que os objetivos não sejam atingidos, já que a análise que se faz da informação pode estar errada ou simplesmente pode não ter considerado os diferentes fatores que intervêm na geração do produto ou serviço, razão pela qual o segundo parâmetro que se deve ter em conta, é que a entidade deve investir na melhoria dos canais de comunicação no interior e no exterior, assim como também se deve contar com indicadores objetivos que permitam analisar seu desempenho, e melhorar o processo de retroalimentação necessário para redirecionar as políticas quando for necessário.

\footnotetext{
${ }^{58}$ HERRERA, Gomez Manuel. Liberalismo versus comunitarismo, seis voces para un debate y una propuesta. Navarra: Garrigues Catedra Universidad de Navarra; Thomson Aranzadi, 2007. p. 133.

${ }^{59}$ HERRERA, Gomez Manuel. Liberalismo versus comunitarismo, seis voces para un debate y una propuesta. Navarra: Garrigues Catedra Universidad de Navarra; Editoria Thomson Aranzadi, 2007. p. 134.

${ }^{60}$ MACINTYRE, 1981, apud, HERRERA, Gomez Manuel, Liberalismo versus comunitarismo, seis voces para un debate y una propuesta. Navarra: Garrigues: Catedra Universidad de Navarra; Thomson Aranzadi, 2007. p. 139.
} 
A respeito, a ex-presidente do Chile, Michelle Bachelet, em entrevista com o jornal "El Tiempo" da Colômbia ${ }^{61}$ quando lhe perguntaram que lição tinha aprendido com as realizações da sua administração, respondeu:

La esencia de esto es que uno nunca debe enamorarse de sus obras. Tiene que estar permanentemente fiscalizando, revisando y supervisando que las políticas públicas efectivamente tengan en el centro a las personas, porque muchas veces la gente se enamora de una idea, de un sistema, pero finalmente cuando uno lo evalúa al cabo de unos años no cambió para nada las condiciones. Y en eso uno tiene que tener toda la humildad como gobernante, la responsabilidad $y$ la honestidad de reconocer lo que funciona y lo que no funciona, y eso requiere de un Estado capaz de evaluarse así mismo.

North afirma que:

La mejor receta para enfrentar esas situaciones novedosas (típicas del mundo de cambios continuos y novedosos en el que vivimos) es la que Hayek expuso hace muchos años $y$ que ha sido el origen del éxito material de Estados Unidos, a saber, el mantenimiento de las instituciones que permiten la realización de experiencias de ensayo y error. Esa estructura implica no solo una diversidad de instituciones $y$ organizaciones a fin de que puedan probarse políticas alternativas, sino también medios eficaces de eliminar las soluciones fallidas. La eficiencia adaptativa solo evoluciona luego de un periodo relativamente extenso de desarrollo de las normas informales, y no conocemos forma alguna para acortar este proceso. ${ }^{62}$

Adicionalmente, outro problema que se apresenta é a retroalimentação imperfeita, para a qual, North assinala o seguinte:

Si tuviéramos una retroalimentación perfecta sobre las consecuencias de nuestras políticas institucionales, podríamos entender correctamente si nuestros actos han alcanzado los objetivos buscados. Sin embargo, hay tanto "ruido" en el sistema que aun cuando quisiéramos entender los resultados

${ }^{61}$ BACHELET, Michelle. Disponível em: <http://www.eltiempo.com/archivo/documento/ CMS-7740728>. Acesso em: 15 jul. 2010.

${ }^{62}$ NORTH, Douglass C. Para entender el proceso de cambio económico. Tradução Horacio Pons. Bogotá: Norma, 2007. p. 235. 
seriamos quizás incapaces de detectar señales claras, y los problemas entre autoridades y agentes en la cadena jerárquica de la información que generan la retroalimentación pueden contrarrestar la posibilidad de una evaluación correcta. Mejorar el desempeño de una economía lleva su tiempo, mucho más prolongado que el horizonte temporal del político que debe aprobar tales cambios. ${ }^{63}$

O terceiro parâmetro que consideramos básico para a melhora das entidades é a existência de ordem em todos os níveis das entidades. Isso implica vários aspectos que deverão ser analisados em cada entidade, mas, de maneira geral, alguns deles podem ser elencados: cada funcionário deve ter clareza dos seus limites, ou seja, de sua competência e de sua responsabilidade dentro das atividades, assim mesmo, os documentos que suportam as diferentes atividades da entidade devem estar bem catalogados e identificados; deve existir também clareza das normas que são aplicáveis, assim como dos requisitos legais e técnicos em cada instituição, assim como canais claros de comunicação que permitam uma retroalimentação efetiva.

Finalmente, em nosso conceito, um costume bem arraigado dentro das culturas latinas é a incapacidade de reconhecer os próprios erros, seja pelo medo da aplicação de algum castigo ou de ser julgado, ou medo de perder autoridade. Esse costume impede que se tomem medidas corretivas ou preventivas, o que gera maior ineficiência nas ações do Estado. Assim, o quarto e último parâmetro, que consideramos fundamental, é começar a trabalhar uma cultura do autocontrole que aceita os erros como primeiro passo necessário para a melhora contínua. Aceitar os erros implica tomar ações corretivas e de melhora que impeçam que o mesmo erro seja cometido novamente.

\section{Considerações finais}

O Estado é um agente fundamental para o processo de desenvolvimento econômico e social dos países, razão pela qual o fortalecimento das entidades e

\footnotetext{
${ }^{63}$ NORTH, Douglass C. Para entender el proceso de cambio económico. Tradução Horacio Pons. Bogotá: Norma, 2007. p. 228.
} 
instituições deve ser um objetivo permanente dentro das políticas públicas dos governos, se se tem como finalidade realizar o cumprimento da Constituição e da lei.

O estudo das diferenças entre a Revolução Americana, a Revolução Francesa e do Caso Latino-Americano, mostra claramente que os costumes, ideias e práticas aceitas pelas comunidades ou sociedades em cada época, condicionam fortemente a aplicação e interpretação das Constituições e as leis, gerando instituições únicas e diferentes em cada contexto.

Por esse motivo, é importante estudar cada instituição dentro do contexto histórico em que se desenvolveu, com a finalidade de determinar os condicionamentos culturais e as práticas aceitas pelas pessoas que dão vida a essa instituição, já que, com um diagnóstico claro, é possível determinar as ações necessárias para melhorar seu desempenho, assim como o tipo de reeducação necessária para mudar as práticas que não estejam acordes à Constituição ou a lei.

Dessa forma, é importante que os governantes e os cidadãos sejam conscientes de que todo processo de mudança institucional é lento e precisa de trabalho contínuo, assim como também precisa de uma participação mais ativa de todos nos assuntos do Estado.

Em decorrência, para que as Constituições sejam realidade, é necessário trabalhar na reeducação tanto de governantes como de governados, principalmente em países com antecedentes de regimes autoritários (como Brasil e Colômbia), já que a simples enunciação dos direitos e das garantias não é suficiente para gerar alterações efetivas na sociedade.

Assim, concordamos com a ênfase que faz MacIntyre a respeito da importância de trabalhar sobre as práticas sociais e históricas em cada sociedade, mediante um processo de reeducação das pessoas, com a finalidade de criar critérios objetivos para a construção de uma concepção comum e racional do bem; acorde com os parâmetros estabelecidos na Constituição, especialmente no interior das entidades públicas. 
Finalmente, consideramos que as universidades e centros de formação têm uma alta responsabilidade na construção de Estados mais democráticos e respeitosos da Constituição e a lei, em dois aspetos fundamentais; o primeiro, mediante a pesquisa, estudo, análise e avaliação de instituições ou entidades públicas específicas, e o segundo, mediante a construção de programas de curto, médio e longo prazo, que integrem os resultados das pesquisas ao debate acadêmico.

\section{Institutions and historical dependence}

\section{Abstract}

The strengthening of the State should begin by each of the public entities that compose it, by understanding the various formal and informal institutions existing in each of them, as well as mechanisms for enforcement of existing rules. Only by understanding each institution within its cultural context, is possible to target accurately the development and effectiveness of State actions. This study will examine the role of institutions in the progress or the stagnation of society, emphasizing the importance of recognizing the historical limitations that exist in every society and every institution in order to improve the effectiveness of public policies and state actions.For this, the first chapter will examine the concept of institution, the second will be a short resume of the American Revolution, the French Revolution and the Latin American case, in order to show how changes in formal laws are not enough to create institutions capable of promote well-being into the society and in the third chapter, we will try to establish basic and general parameters that public institutions should follow in order to achieve greater effectiveness within the society in which it develops. In our concept, it is important to start working on the construction of different mechanisms that promote a re-education into the society, especially within public entities, for which it is very important that universities and educational centers help through programs of short, medium and long term, and help in monitoring and evaluation of specific institutions.

Keywords: Institutions. Effective public policies. Re-education of public entities. Historical dependence. 


\section{Referências}

ARAGON REYES, Manuel. La Constitución como paradigma: teoría del neoconstitucionalismo: ensayos Escogidos. Edición de Miguel Carbonell. Madrid: Trotta, 2007.

ARENDT, Hannah. Da revolução. Tradução Fernando Dídimo Vieira. Revisão da tradução Navarro de Toledo. Brasília: Ática; Universidade de Brasília, 1988.

BARROSO, Luiz Roberto. Fundamentos teóricos e filosóficos do novo direito constitucional brasileiro. In: (Org.) A nova interpretação constitucional: ponderação, direitos fundamentais e relações privadas. 3. ed. rev. Rio de Janeiro: Renovar, 2008.

BEJARANO, Ana María. La Constitución de 1991: un proyecto de construcción institucional. Bogotá: TM, 1999.

BONILLA, Daniel; JARAMILLO, Isabel Cristina. Ronald Dworkin la comunidad liberal. Bogotá: Siglo del Hombre, 2004.

BREWER-CARÍAS, Allan. Reflexiones sobre la la revolución norteamericana (1776), la revolución francesa (1789) y la revolución hispanoamericana (1810 - 1830) y sus aportes al constitucionalismo moderno. 2. ed. ampl. Bogotá: Universidad Externado de Colombia, 2008. (Derecho Administrativo, n. 2).

CAMBELL, Tom. La justicia: los principales debates contemporáneos. Barcelona: Gedisa, 2002.

DERRIDA, Jacques. Forca de lei: o fundamento místico da autoridade. Tradução Leyla Perrone-Moises. São Paulo: M. Fontes, 2007.

HERRERA GOMEZ, Manuel. Liberalismo versus comunitarismo, seis voces para un debate y una propuesta. Navarra: Garrigues Catedra Universidad de Navarra; Thomson Aranzadi, 2007.

KELSEN, Hans. Teoria pura do direito. Tradução de João Baptista Machado. Revisão para a edição brasileira Silvana Vieira. São Paulo: M. Fontes, 1987.

MOUFFE, Chantal. The democratic paradox. Essex: Verso, 2000.

MOUFFE, Chantal. O regresso do político. Lisboa: Gradiva. 1996. 

64 Rev. Bras. de Políticas Públicas, Brasília, v. 1, n. 1, p. 35-64, jan./jun. 2011
Diana Carolina Valencia Tello

NORTH, Douglass C. Instituciones, cambio institucional y desempeño económico. Tradução Agustin Bárcena. México: Fondo de Cultura Económica, 2006.

NORTH, Douglass C. Para entender el proceso de cambio económico. Tradução Horacio Pons. Bogotá: Norma, 2007. 